\title{
Maps as Special Collections: Bibliographic Control of Hidden Material at Yale University
}

IN THE YEARS FOLLOWING THE 2003 CONFERENCE on "Exposing Hidden Collections," held at the Library of Congress - and the subsequent publication of the Association of Research Libraries (ARL) Task Force on Special Collections' white paper entitled Hidden Collections, Scholarly Barriers: Creating Access to Unprocessed Special Collections Materials in America's Research Libraries - many institutions and repositories have made concerted efforts to address the formidable challenges involved in "exposing" unprocessed and/or underprocessed collections. Exemplary efforts range from a national program initiated by the Council on Library and Information Resources (CLIR) and funded by the Andrew W. Mellon Foundation "to identify and catalog hidden special collections and archives," provide database access to their unprocessed/underprocessed collections. ${ }^{2}$

In addition to the special collections material most often involved in these undertakings (monographs, archives, and ephemera, to name a few) another type is often overlooked: cartographic materials. As noted by Paige G. Andrew, Faculty Maps Cataloging Librarian at the Pennsylvania State University Libraries, "Collections of maps, atlases, globes, and most recently electronic forms of cartographic material typically are the last, or one of the last, kinds of library material given the necessary attention and funding by library administrators." ${ }^{\prime 3}$ In part, this lack of attention can be explained by the amount of time it takes to catalog maps, especially those that are single sheets, and the fact that to do so "requires advanced cataloging ability, as well as knowledge of technical map features and mathematical data."4 In ad-

1. Council on Library and Information Resources, "Cataloging Hidden Special Collections and Archives: Building a New Research Environment (2008)," available online at www.clir.org/hiddencollections/index.html [accessed 1 January 2012].

2. Northwestern University Libraries, "'Hidden Collections' Database," available online at www. library.northwestern.edu/collections/hidden/ [accessed 14 February 2011]; University of Maryland Libraries, "Special Collections' Hidden Collections in Hornbake Library," available online at www.lib. umd.edu/TSD/CATDEPT/spec_coll_uncat_hornbake.html [accessed 1 January 2012].

3. Paige G. Andrew, "A Survey Technique for Map Collection Retrospective Conversion Projects." Cataloging \& Classification Quarterly 27, no. 3 / 4 (1999): 406.

4. Sue Ann Gardner, "A Proposal for Core Level Map Cataloging: Brief Records May Be Best," Nebraska Library Association Quarterly 31, no. 4 (Winter 2000): 31. 
dition, the sheer number of maps that need to be cataloged is often overwhelming.

For libraries whose collections contain large numbers of unprocessed and/or uncataloged early printed maps, ${ }^{5}$ these challenges are compounded, since "the librarian working with early printed maps must be conscious of how the rarity and value of the materials intensify the purposes of cataloging." 6 Records for early maps must frequently include more data than do those for modern maps, as is the case with catalog records of other special collections that also require a more detailed bibliographical description than corresponding "regular" material. This additional information serves two purposes: it allows for the identification of specific editions, impressions, and/or issues of the earlier maps; and it provides a "more exact description of the [map] as an artifact." ${ }^{\prime 7}$ When atlases, atlas factices, ${ }^{8}$ and maps found in books are added to this equation, the processing and cataloging of early cartographic materials becomes yet more complicated. As a result, very few institutions can devote the necessary resources to properly catalog and make these items accessible.

In recent years, the increasingly lucrative commercial trade in early maps has forced many institutions and repositories to reevaluate their map collections. A map once considered of little monetary value, and handled accordingly, can now be worth a considerable amount on the open market. This continuing change in the commercial value of maps requires a concomitant increase in the oversight of institutional map collections. As noted in the Association of College and Research Libraries' (ACRL) "Guidelines on the Selection and Transfer of Materials from General Collections to Special Collections," it is the responsibility of librarians to "identify the rare and valuable materials currently held in general and open stacks" and to transfer these materials to a secure environment. In addition, local procedures for cataloging review and processing, if not already in place, should be developed and implemented. ${ }^{10}$ Once the cartographic material is segregated from the general collections, librarians and administrators must then ensure adequate

5. Within the cataloging profession, "early" printed works traditionally predate 1801 , roughly before the introduction of machine-press printing. The Map Department at Yale defines maps printed prior to 1850 as "early" material.

6. Nancy A. Kandoian, "Cataloging Early Printed Maps," Cataloging \& Classification Quarterly 27, no. 3/ 4 (1999): 231.

7. The importance of these criteria in enhanced bibliographical descriptions is outlined in Descriptive Cataloging of Rare Materials (Books) (Washington, D.C.: Cataloging Distribution Service, Library of Congress, 2007), 12 ("Need for special rules").

8. Atlas factices, or composite atlases, are collections of previously issued maps, bound or loose-leaf, gathered by a client or collector usually without a printed title page, table of contents, printed pagination, or index.

9. ACRL Rare Books and Manuscripts Section Task Force to Review Guidelines on the Selection and Transfer of Materials from General Collections to Special Collections, "Guidelines on the Selection and Transfer of Materials from General Collections to Special Collections," C\&RL News (Nov. 2008): 630.

10. Ibid., Appendix II. Changing Catalog Records. 
collection security, while at the same time balancing the needs of scholars and patrons to have access to the material. ${ }^{11}$

Even in institutions where early maps are kept in secure environments, they quite often remain unprocessed or underprocessed. As a result, they may be more vulnerable to loss or theft, and are basically inaccessible to scholars and patrons. And although these materials might be "discovered," their retrieval is often cumbersome and time-consuming. ${ }^{12}$ In the past decade, a number of institutions have completed successful retrospective conversion projects for cartographic materials that have included early maps in their collections-but only if a catalog card for each map had been filed in the original card catalog. Retrospective conversion, at its best, can only transcribe what is on the catalog cards, and since many cards (and especially ones for early maps) provide only minimal information, the resulting online bibliographical records often fail to accurately describe what is in the collection.

All of these issues uncomfortably came to light at Yale University's Sterling Memorial Library in the months following the June 2005 arrest of E. Forbes Smiley, who was eventually convicted in the theft of ninety-seven maps from six institutions, including Yale's Beinecke Rare Book and Manuscript Library and Sterling Memorial Library. A subsequent inventory, undertaken to ensure that all cartographic materials were accounted for in the collections of Sterling's Map Department (previously called the Map Collection), clearly illustrated the lack of proper cataloging and security for many items, a problem demanding action. Among the most pressing issues requiring immediate attention were the following:

1. Lack of inventory control. Prior to the Smiley thefts, no inventory of the collection, for either modern or early maps, had been conducted since the opening of the Map Department in 1950. This lack of control made determining what was missing a very difficult task.

2. Minimal bibliographical control. Although in most cases catalog cards had been created by Map Department staff as maps were acquired, the information recorded often included little more than the author's name (if applicable), title, statement of scale, imprint, and publication date. Notes were sometimes added to the cards, but rarely to distinguish such bibliographical details such

11. ACRL/RBMS Security Committee, "Guidelines for the Security of Rare Book, Manuscript, and Other Special Collections," Association of College \& Research Libraries, available online at www.ala. org/ala/mgrps/divs/acrl/standards/securityrarebooks.cfm [accessed 1 January 2012].

12. Barbara M. Jones, "Hidden Collections, Scholarly Barriers: Creating Access to Unprocessed Special Collections Materials in America's Research Libraries," RBM: A Journal of Rare Books, Manuscripts, and Cultural Heritage 5, no. 2 (Fall 2004): 89. 
as edition or impression. In many instances, the information on the card was inaccurate, since cartobibliographical scholarship has only recently assisted in more precise dating and identification of material. And it was discovered during the inventory that there were instances of early maps having no card at all in the catalog.

Another problem that came to light was that cards produced for maps had never been filed into Sterling's main catalog. Instead, they were kept apart in a separate card catalog located in the Map Department, which was never fully accessible to the public, since it was expected that Map Department staff would always supervise patron use of that catalog. Consequently, when the main library's card catalog was retrospectively converted in the 1980s for inclusion into the library's online public access catalog, cards for maps in the Map Department's catalog were not included. As a result, public knowledge of, and access to, maps located in the Map Department was severely limited.

3. No comprehensive policies or procedures for the processing and cataloging of cartographic material. Although some documentation existed concerning the processing and cataloging of cartographic materials at Yale University libraries, it was very brief, limited to only modern cartographic materials, and not consistently followed throughout the library system. There was no specific guidance for cataloging early printed materials, or mention of the need to catalog these maps at a higher level of bibliographical description.

4. Little or no interdepartmental/library cooperation for processing and cataloging rare maps. The Yale University Library system is in part decentralized, with various outlying departmental libraries operating semi-independently from the main library located on the central campus. At least three major repositories of rare maps exist at Yale: the Beinecke Rare Book and Manuscript Library, the Map Department in Sterling Memorial Library, and the British Art Center. Historically, each library has dealt with its early maps according to internal and localized practices: for example, the Beinecke Library's management of its early maps greatly differed from the practices of Sterling Library. Even in select instances when there had been some interlibrary coordination, nothing describing these efforts was ever codified or necessarily even continued over time.

5. No experienced professional staff to properly catalog early maps. When the decision was made to catalog the early maps in the Map Department, no experienced professional staff was available to do so. There was a map cataloger in the Catalog and Metadata Services Department, but one with limited experience 
in cataloging early material. Conversely, there were rare book/special collections catalogers, but they had little or no experience cataloging early maps. ${ }^{13}$

To address these challenges, a Map Planning Group was appointed in February 2008, charged with developing a plan for cataloging all maps located in the Map Department. (The activities of the Map Planning Group exclusively concerned the collections of Sterling's Map Department; although Beinecke and the British Art Center collections contain significant holdings in early cartographic material, the majority is contained in bound atlases that have adequate bibliographic descriptions.) Consisting of the curator and two staff members from the Map Department, two catalog librarians from the Catalog and Metadata Services Department, and the head of Technical Services of the Beinecke Library, the group outlined three primary goals: (1) to create preliminary bibliographic control for the entire collection by 2011 ; (2) to create full-level catalog records for all early and unique maps by 2013; and (3) to develop procedures for providing full-level catalog records for all modern maps. To achieve these larger goals, it was recommended that two smaller projects be undertaken:

- create preliminary records for all early maps (pre-1850)

- create preliminary records for all modern maps (post-1850)

Once these preliminary records were created, a project for full-level cataloging of all early maps was to proceed, followed by one to create full-level records for all modern maps.

In June 2008, two student workers were hired to work full-time (37.5 hours per week) with Map Department staff to create preliminary records for all early maps that had been identified. It was expected to take three months to add an estimated 9,000 records to the online catalog. ${ }^{14}$ The decision to initially create preliminary rather than full-level records for the early maps was made to quickly provide better bibliographic control, improve security, enhance overall collections management,

13. The issues outlined above are not new to the Map Department at Yale; see Margit E. Kaye, "A Comparison of Major University Map Collections to Determine the Adequacy of and to Propose Improvements to the Yale University Map Collection," Bulletin (Special Libraries Association. Geography and Map Division) no. 168 (June 1992): 2-23, especially concerning the lack of public access to material, minimal bibliographic control, and the need for retrospective conversion of the Map Collection's card catalog.

14. The hiring of student workers to efficiently complete short-term cataloging projects for uncataloged/underprocessed special collections has been used by a number of institutions and repositories in the past few years; for two such examples, see M. Winslow Lundy, "Providing Access to Uncataloged Special Collections with In-Process Records," Cataloging \& Classification Quarterly 45, no. 1 (2007): 39-58, and "University of Chicago Ph.D. Students Assist with Uncovering Hidden Collections," Illinois Library Association Reporter 24, no. 6 (Dec. 2006): 30-31. 
and assist in the beginning stages of digitization efforts. ${ }^{15}$ Thus, no copy catalog searching and no authority work were to be undertaken. Although the students would input information from the catalog cards, all the maps would also be examined to ensure that data matched the item in hand. Several days were spent training the students in understanding MARC formatting and record creation, including attaching holding- and item-level (barcoded) records. The latter process of assigning barcodes was very important, as it enabled the Map Department to better track material movement, in addition to providing more adequate bibliographic control for any future inventory. Review of the work was done periodically by spot-checking portions of the collection (records input by the students were easily retrieved by a keyword search on the term "preliminary record").

The Map Planning Group engaged in lengthy discussions to determine what data should be included in a preliminary record. Historically, all bibliographic records created in the Catalog and Metadata Services Department at the preliminary level were considered temporary in nature; they would subsequently be upgraded to full-level. Thus, little consideration had been given to what specific information should be included in these records. This was especially true in the case of preliminary records for early printed maps, as few (if any) such records had ever been made for this type of material.

Keeping in mind the ultimate goal of creating full-level bibliographic records for all the early maps, the Map Planning Group identified the following MARC fields as required in a preliminary record. This information would be transcribed from the catalog card or supplied if not found on the card:

034 (coded cartographic mathematical data): provided only if scale of the map was given on the catalog card

245 (title, other title information, and statement of responsibility)

255 (statement of scale) [e.g.: Scale 1:250,000]

260 (place, publisher, and date of publication)

300 (physical extent of item)

590 (copy-specific note): would include the phrase "preliminary record" to easily parse out the Map Department's records when searching the online catalog; searching in the staff mode could be further refined by limiting the location code to, for example, the Map Department.

651 (subject-added entry, geographic name): all preliminary records would contain at least one subject heading (easily determined by the local clas-

15. These considerations roughly correlate to Gardner's (ibid.) summations for creating core records for maps: reduce the complexity of cataloging; save time; increase the number of records created; and improve access. 
sification code given on the map, which was geographically organized); ${ }^{16}$ for all pre-1800 maps, the free-floating subdivision "Early works to 1800 " was to be added.

655 (form/genre headings): taken from the Library of Congress Thesaurus for Graphic Materials form/genre heading "Maps" including the geo-

graphical area depicted in hierarchical order (that is, reverse), with date of publication, such as 655: 7: $\neq$ a Maps $\neq z$ Connecticut $\neq z$ New Haven $\neq$ y 1701. $\ddagger 2$ lctgm. ${ }^{17}$

Concurrent with the creation of preliminary records for rare maps, a project was initiated to provide full-level records for the Cross Collection, a small subcollection of about 400 early printed maps, to: (1) test the recently designed workflow for rare maps; (2) test the standards developed for cataloging "full" records for rare maps; and (3) determine the respective roles of catalog librarians and cataloging assistants in the complete process. It was intended that the Cross Collection would be cataloged by the Map Catalog Librarian in Sterling's Catalog and Metadata Services Department; but, following this librarian's departure from the university in May 2008, the Map Planning Group requested that a catalog librarian from the Rare Book Team assume responsibility. Cataloging this collection thus required a close working relationship between the rare book cataloger and staff in the Map Department. In addition to the physical retrieval and shelving of the material, Map Department staff was to provide assistance in locating appropriate cartobibliographical reference sources, as well as contribute their invaluable input in issues relating to map cataloging.

The student-assisted project to enter preliminary records for the rare maps was completed in August 2008. In 749 hours, staff pulled 9,372 maps, created 6,342 preliminary records, and identified 2,577 records already in the online catalog. Including both searching the online catalog for existing records and creating preliminary records, staff averaged twelve maps per hour. Since completing this project, the Map Department has records in the online catalog for nearly all its pre-1850 maps (there remain a handful of maps in non-Roman script that have to be cataloged by staff with language skills specific to the material).

With all but a few exceptions, the project to provide full bibliographical records for the Cross Collection was completed in November 2008 (about 20 maps from the collection remain to be cataloged). In 197 hours (including associated research and

16. For the Yale Map Department's classification codes, see www.library.yale.edu/cataloging/cartographic/Map_Collection_Call_Number_System.xls [accessed 1 January 2012].

17. The MARC source code in the 655 tracing for cartographic materials is now coded lcgft for Library of Congress Genre/Form Terms for Library and Archival Materials; the Yale Library is currently in the process of updating the "lctgm" coding for cartographic materials to "'lcgft" to reflect this change. 
consultation of specific cartobibliographical resources), 431 maps were cataloged, 92 of which required original records. On average, it took forty-five minutes per map to create a full-level bibliographic record.

As both these projects progressed, the Map Planning Group created, tested, and updated a wide range of map cataloging and processing documentation. ${ }^{18}$ Seeking to address deficient or previously nonexistent policies and workflow for cataloging cartographic materials, the documentation covered record creation (preliminary, minimal-level, full-level, copy, and original cataloging) and identified specific local practices related to call numbers and physical marking. There was also a concerted effort to delineate distinct polices, procedures, and workflow for pre-1850 cartographic material, with an emphasis on enhanced bibliographic descriptions, provenance tracing, and generous use of genre terms. ${ }^{19}$ These policies were written with the objectives and principles of Descriptive Cataloging of Rare Materials (DCRM(B)) in mind-specifically, clearly distinguishing between different manifestations of a work, while also increasing the efficiency of patron and/or collection management access. Such enhanced bibliographical descriptions also improve the security of the collection, since the library now has a more accurate record of its holdings.

To further increase the security of the collection, barcoding and scanning of all pre-1850 maps has been incorporated into the project workflow. For pre-1850 maps encased in Mylar, a barcode is affixed to the Mylar covering; those not in Mylar receive a barcode printed on a sheet of acid-free paper housed in the folder containing the map. Barcoding the collection will also assist in more efficient workflows, enable Map Department staff to more easily track circulating material, and will make future inventory control less time-consuming. The final step in the processing workflow is scanning the map, done in-house by Map Department staff, and linking the digital image to the bibliographical record using the MARC 856 field. Two separate image files are created for each map: a TIFF file master image for archival purposes (which can also be given to researchers when requested); and a derivative JPEG 2000 version, which is the one attached to the bibliographical record. (Viewing this image requires downloadable LizardTech software, available through the Map Department's Web site.) Although the digital images are currently accessible only through the online catalog record, scanning the early maps will facilitate a long-term Map Department goal of folding all of its locally stored digital files into the centralized Yale University Library’s Digital Collections. Incorporating map im-

18. The main documentation portal for cataloging cartographic material at Yale University Library can be found at "Cataloging Cartographic Materials at Yale University Library" on Yale University Library's "Cataloging at Yale" Web page, available online at www.library.yale.edu/cataloging/cartographic/index.htm [accessed 1 January 2012].

19. This documentation can be found under "Cartographic Materials" on the "Beinecke Cataloging Manual" page on the Beinecke Rare Book and Manuscript Library's Web page, available online at www. library.yale.edu/BeinCatM/home.html [accessed 1 January 2012]. 
ages into Digital Collections will publicly illustrate the "special collections" nature of early printed maps, and, it is hoped, "increase use of the material, contribute to new forms of research, and attract new users to the material." ${ }^{20}$ Just as important, creating and disseminating digital images of early maps will reduce the handling and circulation of the paper originals.

As of January 2012, nearly all pre-1850 maps in the Map Department (about 12,000 items) have a bibliographic record in the online catalog (a majority now represented by preliminary records, with a small portion having full-level records). Nearly 3,000 of these 12,000 maps have been scanned. Although part-time student workers were hired in early 2008 to complete the bar-coding and scanning processes, budgetary constraints faced by the library (and the university in general) that began in late 2008 necessitated the postponement of the scanning portion. The short-term goal of the Map Department and the Map Planning Group is first to complete this project (including rehiring staff to complete the scanning of the remaining pre-1850 maps) and then to upgrade the preliminary records for all pre-1850 maps to full-level cataloging. Achieving this latter goal will require hiring a professional catalog librarian dedicated full-time to cataloging cartographic materials.

During the past three years, the Map Department has made enormous progress in identifying and improving access to its collections, especially its early printed maps. The challenges brought to light in the wake of the highly publicized thefts of valuable maps from Yale's collections have been addressed in a systematic and comprehensive manner. A complete inventory of the Map Department's collection has been conducted; bibliographical control of material improved; a wide range of policies and procedures for all staff cataloging cartographic materials developed; and cooperation between different departments and libraries handling cartographic materials dramatically increased.

One of the vital lessons learned through this whole process has been the need for interdepartmental/interlibrary input and cooperation. The Map Planning Group was deliberately composed of a wide range of staff (professional, paraprofessional, clerical, and technical) from three different units located in two separate libraries: Technical Services in Beinecke and both the Map Department and Catalog and Metadata Services in Sterling. The accomplishments of the group have clearly shown the strength of diversity in decision making and problem solving.

Since the Map Planning Group instituted the new policies and procedures for the Yale Library as a whole, the Beinecke Library has begun to address its specific

20. Peter B. Hirtle, “The Impact of Digitization on Special Collections in Libraries,” Libraries \& Culture 37, no. 1 (Winter 2002): 44. 
cartographic collection needs, including a comprehensive inventory and increased cataloging of its atlases (which involves the cataloging of individual maps within the atlases). Additionally, the rare book cataloger at the British Art Center (BAC) has worked closely with a rare book cataloger at the Beinecke to implement the new policies in its effort to catalog cartographic resources. Sterling's Map Department has made its collections more accessible and to a wider audience, while at the same time ensuring appropriate security. In particular, early printed maps, previously a "locked" and "hidden" special collection, are now represented in the online catalog, many with digital images that can be retrieved by patrons both within and outside the Yale community.

Despite these many successes, many issues remain unresolved. The precipitous decline of the university's endowment after 2008 had an enormous impact on the operations and staffing of departments and libraries across campus. In this new fiscal environment, the pressures of providing the same level of service and productivity within severely constrained budgets are great. For nearly two years, the Map Department had to temporarily put "on hold" its projects to create full-level records for the early and modern maps, as well as freeze the digitization of the remainder of its early maps.

Despite this, institutional policies, procedures, and workflow documentation are in place, and the cooperation that has been established among libraries and departments has enabled the smooth continuance of the other parts of the project as the budget situation has improved. In January of 2011, two full-time clerical and technical employees were hired for two-year term positions, with the primary goal of providing bibliographic control of all post-1850 maps (about 7,350 sheets). For those titles not already in the online catalog, this would be accomplished either through copy-cataloging or creating preliminary records using information from catalog cards when no useful copy is found. Although the initial plan for the modern maps called for the creation of only preliminary records, it was decided that searching for cataloging copy in OCLC might prove fruitful for these items too. (Indeed, this has been the case; twelve months into the project, usable copy had been found for 32 percent of the material handled.) As of January 2012 (half-way through the project), 83 percent of the post-1850 maps have been processed, with over 6,000 sheets handled (this number includes multi-sheet titles) and 2,700 new bibliographic records entered into the online catalog. It is estimated that the project will successfully achieve its goal of providing bibliographic records for all post-1850 maps within the remaining twelve months.

The challenges faced by the Yale University library system in dealing with its holdings of early printed maps are not specific to this institution or to the current 
financial environment: countless other institutions and repositories find themselves in similar circumstances. While the procedures devised by the Map Cataloging Group at Yale are most certainly not the final word on how to address these problems, perhaps understanding these processes and decisions will assist others in their attempts to formulate a workable solution to their challenges. In approaching these issues, librarians and/or institutional staff must always keep in mind that it is their professional responsibility to ensure both proper access and security for their collections. This involves creating and implementing comprehensive policies and procedures for processing and cataloging collections, establishing sensible and effective workflows, and, most important, fostering and promoting trust and cooperation among colleagues tasked with carrying out the new policies, procedures, and workflows. Collections that are improperly processed or cataloged are of limited use. The future value of collections held by repositories and libraries can only come about through the consistent vigilance and hard work by library staff and administrators today.

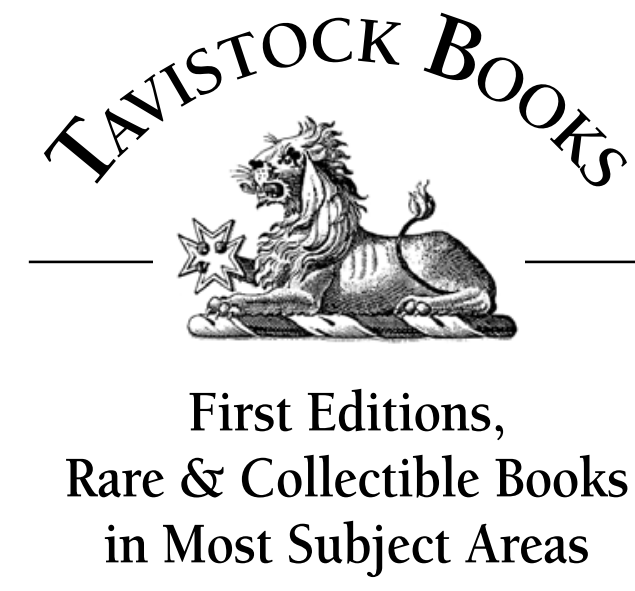

WWW.TAVBOOKS.COM

AB SECURE - SEARCHABLE

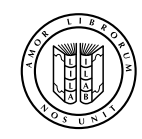

1503 WEBSTER STREET • ALAMEDA, CALIFORNIA 94501

T: 510.814.0480・F: 510.814.0486・vjz@tavbooks.com 